\title{
Risk Factors of Urinary Incontinence in Bahrain
}

\section{Zainab A. Al-Jufairi ${ }^{1}$, Wadeea H.Gherbal ${ }^{2}$ and Fadheela S. Al-Najjar ${ }^{3}$}

${ }^{1}$ FRCOG, MHPE, CABS, Consultant OB/GYN, Salmaniya medical Complex, Kingdom of Bahrain

${ }^{2} M S B$, Senior resident, Department of OB/GYN, Salmaniya medical Complex, Kingdom of Bahrain

${ }^{3}$ Consultant $O B / G Y N$, Alkindi hospital, AFS, AFSA, CABS, Kingdom of Bahrain

Abstract
Objective: To determine the risk factors for urinary incontinence (UI) amongst the patients attending
the Urogynecology clinic in Salmaniya medical Complex.
Design: Cross sectional study.
Setting: Salmaniya Medical Complex - Urogynecology clinic.
Population: A total of 259 women complaining of stress and mixed urinary incontinence were recruited
between January 2005 and December 2011 . Women with over active bladder syndrome, pure neurogenic
bladder and overflow incontinence were excluded.
Methods: Data collected from the recording forms which were used regularly in the urogynecology
clinic.
Results: The risk of urinary incontinence increased significantly with age. Women aged $30-60$ years
were approximately 3-6 times more likely to develop urinary incontinence than women less than 30 years.
The risk of UI was increased by obesity (OR 2.5, $95 \%$ CI (1.6-4.1), vaginal delivery (OR 6.73, $95 \%$ CI $1.2-$
36.8), parity (Para 3-5) (OR 5.09, $95 \%$ CI 5.6-9.8), postmenopausal status (OR 5.57, 95\%CI 3.2 -9.8) and
chronic pulmonary diseases (OR 4.00, 95\%CI 1.1 -14.2).
Conclusions: The significant risk factors for UI as seen in our study population were age, body mass
index, parity, vaginal delivery, menopause and chronic pulmonary diseases.

\section{Publication History:}

Received: September 02, 2014

Accepted: October 29, 2014

Published: October 31, 2014

\section{Keywords:}

Stem cell, Cell therapy, Urinary incontinence

\section{Introduction}

Urinary incontinence (UI) is defined by the International Continence Society Standardization Committee as "any involuntary leakage of urine". Urinary incontinence can be classified into stress incontinence, urge incontinence and mixed incontinence. Stress incontinence is defined as "involuntary leakage on effort or exertion, or on sneezing or coughing". While urge urinary incontinence is defined as "the complaint of involuntary leakage accompanied by or immediately preceded by urgency". On the other hand, mixed urinary incontinence is "The complaint of involuntary leakage associated with urgency and also with exertion, effort, sneezing or coughing" [1].

Studies have shown that urinary incontinence affects women of all ages but it rises with advanced age. The prevalence of UI is estimated to range from $16 \%$ to $46 \%$ amongst middle-aged women and rise to $50 \%$ in older women [2-4]. Stress urinary incontinence (SUI) is the most prevalent type of urinary incontinence affecting nearly $30-50 \%$ of women [3,5-7]. Urinary incontince is an embarrassing condition with a major impact on a quality of life [7-9].

Several studies had focused on risk factors of urinary incontince and these are important in counseling patients appropriately [2$4,10]$. We decided to study the risk factors of urinary incontinence in Bahraini women as there are no published studies which addressed this issue in our society.

The aim of this study was to find out the risk factors of urinary incontinence amongst the patients who presented to the Urogynecology clinic at Salmaniya Medical Complex with urinary incontinence from 1st of January 2005 till $31^{\text {st }}$ December 2011.

\section{Materials and Method}

This study was conducted in the Urogynecology clinic at Salmaniya Medical Complex (SMC) in Bahrain. SMC is the main tertiary governmental hospital in Bahrain. All women who attended the Urogynecology clinic between $1^{\text {st }}$ of January 2005 till $31^{\text {st }}$ December
2011 with stress urinary incontinence or mixed urinary incontinence or mixed urinary incontinence were included in our study. Women with over active bladder syndrome, pure neurogenic bladder and overflow incontinence were excluded.

The data was collected from the recording forms which were used regularly in Urogynecology clinic at Salmaniya Medical Complex. The form included the following information: Age, weight, BMI, Parity, mode of delivery, menopausal status, recurrent urinary infections, prior hysterectomy or pelvic floor repair and chronic medical illnesses. The form documented the patient complaints of urinary incontinence whether it was stress, urge or mixed incontinence. The data regarding pelvic examination and investigations was included. The diagnosis of stress urinary incontinence was based on history, physical examination and urodynamic study.

Ethical Approval for this research was obtained from Health Research Committee of secondary care.

\section{Statistical Analysis}

The collected data was coded and SPSS software (version 20) was used for statistical analysis. $\mathrm{P}$ value for significance, mean and percentage were used for descriptive statistics and risk was estimated using odd ratio (OR), and 95\% CI. The risk factors of UI were analyzed using Univariate logistic regression test.

"Corresponding Author: Dr. Fadheela S. Al-Najjar, Consultant OB/GYN, Alkind hospital,AFS,AFSA, CABS, Kingdom ofBahrain;E-mail:drfadheela@hotmail.com

Citation: Al-Jufairi ZA, Gherba WH, Al-Najjar FS (2014) Risk Factors of Urinary Incontinence in Bahrain. Int J Gynecol Clin Pract 1: 105. doi: http://dx.doi. org/10.15344/2394-4986/2014/105

Copyright: (C 2014 Al-Jufairi et al. This is an open-access article distributed under the terms of the Creative Commons Attribution License, which permits unrestricted use, distribution, and reproduction in any medium, provided the original author and source are credited. 
Citation: Al-Jufairi ZA, Gherba WH, Al-Najjar FS (2014) Risk Factors of Urinary Incontinence in Bahrain. Int J Gynecol Clin Pract 1: 105. doi: http://dx.doi. org/10.15344/2394-4986/2014/105

Page 2 of 4

\section{Result}

A total of 259 women complaining of urinary incontinence were recruited between January 2005 and December 2011. The mean age was $46.8 \pm 10.6$ (mean $\pm S D$ ). Most of the patients who had UI were in the age group of (30-45) and (46-60) year (Figure 1). BMI of only 122 patients in the study group was documented and it ranged from (20.4 - 58.6). The mean BMI \pm SD was $31.9 \pm 7.09$ and $85 \%$ were overweight or obese (Figure 2).

Out of 259 women included in the study there were: 12 Nulliparous (4.6\%), 33 Para 1-2 (12.7\%), 132 Para 3-5 (50.96\%) and 82 grandmulti $(>5)(31.7) \%$. So the majority of the women with UI had more than two deliveries (Figure 3 ).

When analyzing the obstetric data, it was seen that 243 patients had previous vaginal delivery (92.7\%). The majority were multi-parous; 129 were Para 3-5 (53\%) and 81 were grandmulti (33.3\%)(Figure 4).

Out of 259 women, 107 patients (41.3\%) had rectocele, 219 (84.4\%) had cystocele, $38(14.7 \%)$ had enterocele and $92(35.5 \%)$ had uterine prolapse. Of the study group $6 \%$ underwent hysterectomy and $4.6 \%$ had pelvic floor repair. Thirty percent of the study groups were postmenopausal (77 patients).

The following conditions were associated with UI: recurrent urinary tract infections (34\%), chronic constipation (32\%), diabetes mellitus (17.4\%), spinal diseases (14.3\%), gastrointestinal diseases (12\%), neurological diseases (2\%), (bronchial asthma and chronic obstructive pulmonary diseases $(4.6 \%)$ and $17 \%$ of these patients were on diuretics.

By using univariate logistic regression analysis, the following risk factors were found to be statistically significant: Age, BMI, mode of delivery, parity, menopausal status and chronic pulmonary disease. (Table 1).

Women in the age group 30-45years had a significant increase in risk of developing UI (OR 6.2, 95\% CI (3.5-11). Women in the age group 46-60 years had also a significant increase in developing UI (OR 3, 95\%CI (2.2-4.2). Obese and overweight ladies had a significant rise in developing urinary incontince (OR 2.5). The other significant risk factors in this study were vaginal delivery (OR 6.73, 95\%CI 1.236.8 ), parity (Para 3-5) (OR 5.09, 95\%CI 5.6-9.8), postmenopausal status (OR 5.57, 95\%CI 3.2 -9.8) and chronic pulmonary disease (OR $4.0,95 \% \mathrm{CI} 1.1-14.2$ ). The other medical problems were not found to be significant risk factors for devolving urinary incontinence in our study (Table 1).

\section{Discussion}

This research had focused on the risk factors of UI amongst the patients who attended Salmaniya Medical Complex Uro-gynecology clinic between January 2005 and December 2011.

Several studies indicated that the incidence of urinary incontinence increases with age $[2,3,6,10,12-14]$. Our study showed that women 30-60years of age were approximately 3-6 times more likely to develop stress urinary incontinence than women less than 30years. A similar finding was observed in Tsai and Liu study from Taiwan where women 40-75 years of age had 4 fold rise in developing urinary incontince than women less than 30 years of age [13].

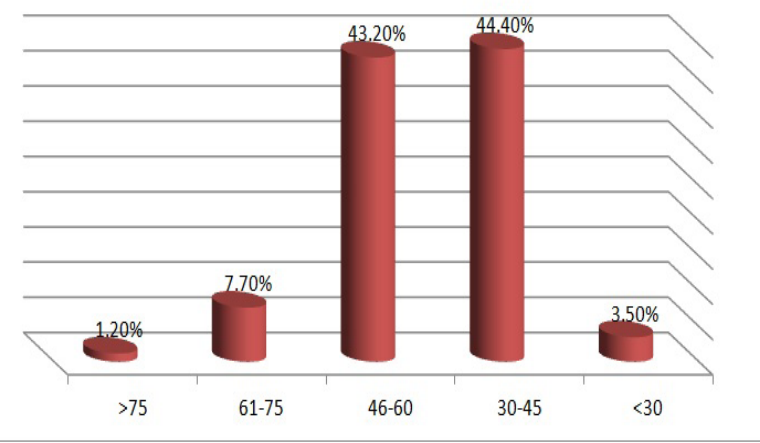

Figure 1: The Age distribution of women with urinary incontince.

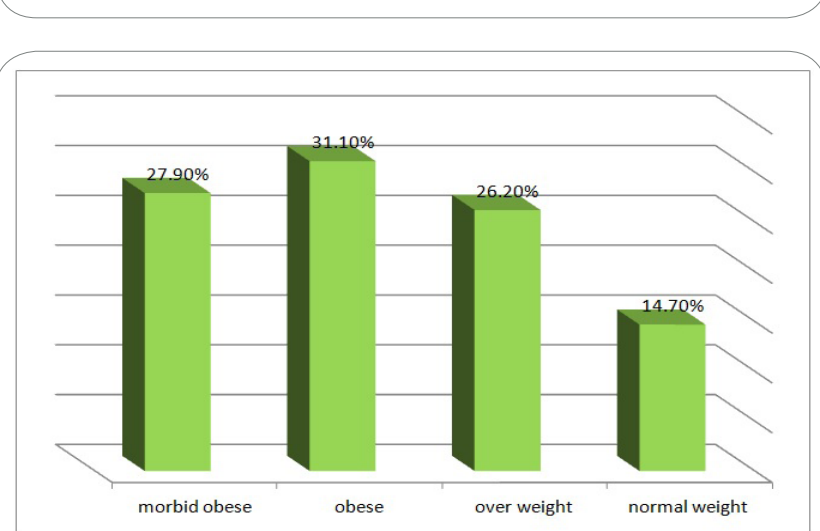

Figure 2: The distribution of BMI amongst women with UI.

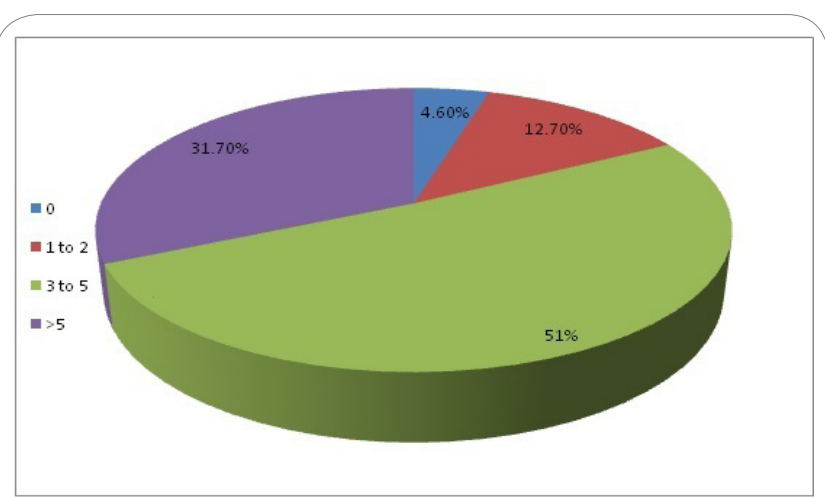

Figure 3: The distribution of parity amongst women with UI.

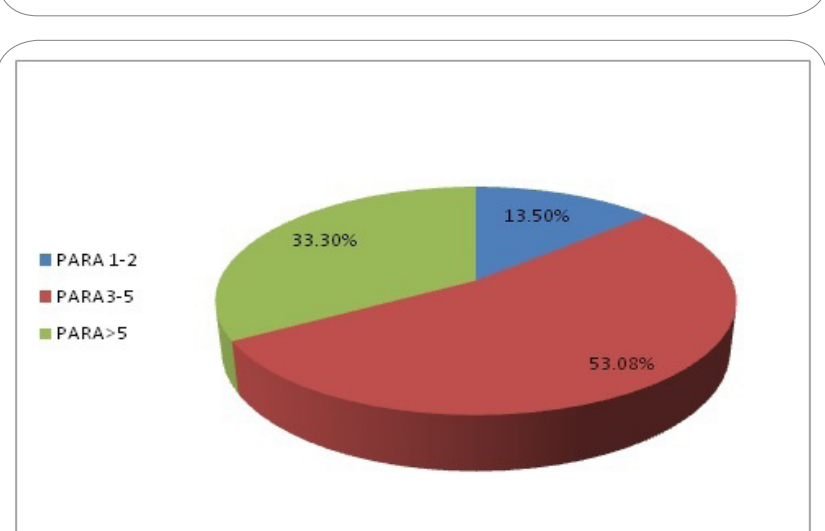

Figure 4: The distribution by parity in normal vaginal delivery. 
Citation: Al-Jufairi ZA, Gherba WH, Al-Najjar FS (2014) Risk Factors of Urinary Incontinence in Bahrain. Int J Gynecol Clin Pract 1: 105. doi: http://dx.doi. org/10.15344/2394-4986/2014/105

Page 3 of 4

\begin{tabular}{|l|l|l|l|l|}
\hline \multicolumn{2}{|l|}{ Risk Factors } & OR & $95 \%$ C.I & P-value \\
\hline \multirow{3}{*}{ Age } & $30-45$ & 6.19 & $(3.49,10.98)$ & $<.001$ \\
\cline { 2 - 5 } & $46-60$ & 3.04 & $(2.17,4.23)$ & $<.001$ \\
\cline { 2 - 5 } & $61-75$ & 1.28 & $(1.03,1.59)$ & 0.02 \\
\hline \multirow{3}{*}{ BMI } & $25-29.9$ & 2.52 & $(1.57,4.06)$ & $<.001$ \\
\cline { 2 - 5 } & $30-34.9$ & 2.48 & $(1.51,4.08)$ & $<.001$ \\
\hline \multirow{3}{*}{ Parity } & $3-5$ & 5.09 & $(2.64,9.81)$ & $<.001$ \\
\hline Chronic Pulmonary Disease & 1.53 & $(1.33,1.76)$ & $<.001$ \\
\hline Normal vaginal delivery & 4.00 & $(1.13,14.18)$ & .032 \\
\hline Vacuum -Forceps & 6.74 & $(1.23,36.84)$ & .028 \\
\hline Cesarean Section & 0.32 & $(0.03,3.73)$ & .362 \\
\hline Post menopause & 1.15 & $(0.31,4.26)$ & .834 \\
\hline DM & 5.57 & $(3.15,9.84)$ & $<.001$ \\
\hline GI & 0.97 & $(0.26,3.54)$ & 0.96 \\
\hline Spinal Diseases & 1.53 & $(0.17,13.74)$ & 0.71 \\
\hline Depression & 4.10 & $(0.46,36.94)$ & 0.21 \\
\hline Constipation & 1.18 & $(0.11,12.45)$ & 0.89 \\
\hline UTI & 0.34 & $(0.11,1.07)$ & 0.07 \\
\hline Hysterectomy & 0.66 & $(0.22,2.04)$ & 0.48 \\
\hline Rectocele & 0.62 & $(0.09,4.19)$ & 0.62 \\
\hline Cystocele & 0.59 & $(0.10,3.58)$ & 0.57 \\
\hline Enterocele & 0.79 & $(0.12,5.44)$ & 0.82 \\
\hline Uterine Prolapse & 0.53 & $(0.15,1.88)$ & 0.33 \\
\hline
\end{tabular}

Table 1: Univariate logistic regression analysis of potential risk factors for UI.

Obesity has been implicated in many clinical trials as a significant risk factor of urinary incontinence [2,3,6,10,12-15]. This strong association can be explained by the increase in intra-abdominal and intra-vesical pressure as a result of increasing body weight [16,17]. Our study showed 2.5 fold increase of UI associated with obesity (95\% CI: 1.5-4). The same findings has been observed in cross sectional studies in Women's Health Australia project, as obese women with a BMI of $30-40 \mathrm{~kg} / \mathrm{m}^{2}$ had 2 folds increased risk of UI as compared with BMI lees than $20 \mathrm{~kg} / \mathrm{m}^{2}$ [18].

Vaginal delivery is associated with an increased risk for urinary incontinence particularly SUI $[12,13,18-20]$. This study showed a significant rise in UI amongst women who have vaginal deliveries (OR: 6.7, 95\%CI: 1.2-36.8). This finding was supported by other studies which showed 2 to 3 fold increase of SUI in women who delivered vaginally $[21,22]$. Viktrup et al found that the prevalence of SUI, 12 years after first delivery was $42 \%$ while the cesarean section during first delivery was associated with a significantly lower risk of SUI [19]. A similar observation was made by Brown et al where women who had a cesarean section before labor or in the first stage of labor were less likely to be incontinent as compared to those who delivered vaginally [23].

Previous studies revealed that bladder neck mobility is increased after forcepsdeliverywith an increasein theriskofstressurinaryincontinence $[24,25]$. However, other studies failed to demonstrate any association of forceps or vacuum delivery with urinary incontinence [19,26,27].
Similarly, our study did not reveal any association between instrumental deliveries and SUI.

Parity or number of deliveries is a widely recognized risk factor for developing UI, especially in women with 3 or more deliveries $[7,10,15,22]$. We found that women who had more than 3 deliveries had 5 fold risk of UI (OR: 5.09, 95\%CI: 2.6-9.8). Other studies indicated that multiple deliveries have double to triple the risk of SUI $[2,12,13]$.

Similarly the correlation between the postmenopausal status and UI has been well established $[28,29]$. In our study, we found that postmenopausal women had a significant increase in UI (OR: 5.57, 95\% CI: 3.15-9.84). Several risk factors for urinary incontince in post menopausal women had been postulated. These include low physical function, recurrent urinary tract infection; atrophic vaginitis and diabetic peripheral neuropathy [29].

Women with chronic obstructive pulmonary diseases were found to have a high risk of urinary incontince $[5,12]$. In our study women with chronic pulmonary diseases have a 4 fold increase in UI. A similar finding was observed in El-Hafnawy study as it was observed that patients with bronchial asthma have 9 fold rise of SUI [12]. On the other hand another prospective survey failed to show any statistically significant difference in the prevalence of UI between patients with or without chronic cough and they attributed the lack of the difference to the protective effect of urinary frequency on UI [30].

Several medical disorders, such as cardiac diseases, depression, diabetes, and hypertension were found to be significantly associated with urinary incontinence [4,15,31-33]. However, we did not observe any such association between these medical disorders and UI.

\section{Conclusion}

Women above 30 years were approximately 3-6times more likely to develop urinary incontinence. The other significant risk factors of UI were obesity, vaginal delivery, parity, postmenopausal status and chronic pulmonary disease.

\section{Recommendations}

A Pelvic floor rehabilitation program should be implemented for all postnatal patients to reduce the risk of pelvic floor weakness and subsequent urinary incontinence. Women should be advised to have an active life style and to have an ideal weight to reduce the risk of UI. Family planning is an important intervention in reducing the incidence of UI. More studies are needed to identify the prevalence and types of Urinary incontinence in our society and the ideal management of these patients.

\section{References}

1. Abrams P, Cardozo L, Fall M, Griffiths D, Rosier P, et al. (2002) The standardization of terminology of lower urinary tract function: report from the Standardization Sub-committee of the International Continence Society. Neurourol Urodyn 21: 167-178.

2. Filiz TM, Uludag C, Cinar N, Gorpelioglu S, Topsever P (2006) Risk factors for urinary incontinence in Turkish women. A cross-sectional study. Saudi Med J 27: 1688-1692.

3. Onur R, Deveci SE, Rahman S, Sevindik F, Acik Y (2009) Prevalence and risk factors of female urinary incontinence in eastern Turkey. Int J Urol 16: 566-569. 
Citation: Al-Jufairi ZA, Gherba WH, Al-Najjar FS (2014) Risk Factors of Urinary Incontinence in Bahrain. Int J Gynecol Clin Pract 1: 105. doi: http://dx.doi. org/10.15344/2394-4986/2014/105

Page 4 of 4

4. Kocaoz S, Bilgili N, Eroglu K (2009) Prevalence and risk factors of urinary incontinence in Turkish Nursing Homes: A cross-sectional study. Pak J Med Sci 25: 18-25.

5. Nygaard, Heit (2004) Stress Urinary Incontinence. Obstet Gynecol 104: 607-620.

6. Danforth KN, Townsend MK, Lifford K, Curhan GC, Resnick NM (2006) Risk factors for urinary incontinence among middle-aged women. Am $J$ Obstet Gyneco 194: 339-345

7. Lasserre A, Pelat C, Gueroult V, Hanslik T, Chartier-Kastler E, et al. (2009) Urinary incontinence in French Women: prevalence, risk factors, and impact on quality of life. Eur Urol 156: 177-183.

8. Balmforth J, Cardozo LD (2003) Trends toward less invasive treatment of female stress urinary incontinence. Urology 62: 52-60.

9. Basak T, Kok G, Guvenc G (2003) Prevalence, risk factors and quality of life in Turkish women with urinary incontinence: a synthesis of the literature. Int Nurs Rev 60: 448-460.

10. Yu HJ, Wong WY, Chen J, Chie WC (2003) Quality of life impact and treatment seeking of Chinese women with urinary incontinence. Qual Life Res 12: 327-333.

11. Persson J, Wolner-Hanssen P, Rydstrom H (2000) Obstetric risk factors for stress urinary incontinence: A population-based study. Obstet Gynecol 96: $440-445$

12. EL-Hefnawy AS, Wadie BS (2011) Severe stress urinary incontinence: Objective analysis of risk factors. Maturitas 68: 374-377.

13. Tsai Y-C, Liu CH (2009) Urinary incontinence among Taiwanese women: An outpatient study of prevalence, co morbidity, risk factors, and quality of life. Int Urol Nephrol 41: 795-803.

14. Luber KM (2004) The Definition, Prevalence, and Risk Factors for Stress Urinary Incontinence. Rev Urol 6: S3-S9.

15. Lee KS, Sung HH, Na S, Choo MS (2008) Prevalence of urinary incontinence in Korean women: results of a National Health Interview Survey. World J Urol 26: 179-185.

16. Subak LL, Richter HE, Hunskaar S (2009) Obesity and urinary incontinence: epidemiology and clinical research update. J Urol 182: S2-7.

17. Noblett KL, Jensen JK, Ostergard DR (1997) The relationship of body mass index to intra-abdominal pressure as measured by multichannel cystometry. Int Urogynecol J Pelvic Floor Dysfunct 8: 323-326.

18. Chiarelli P, Brown W, McElduff $P$ (1999) Leaking urine: prevalence and associated factors in Australian women. Neurourol Urodyn 18: 567-577.

19. Viktrup L, Rortveit G, Lose G (2006) Risk of stress urinary incontince twelve years after the first pregnancy and delivery. Obstet Gynecol 108: 248-325.

20. Skoner MM, Thompson WD, Caron VA (1994) Factors associated with risk of stress urinary incontinence in women. Nurs Res 43: 301-306.

21. Herrmann V, Scarpa K, Palma PC, Riccetto CZ (2009) Stress urinary incontinence 3 years after pregnancy: correlation to mode of delivery and parity. Int Urogynecol J Pelvic Floor Dysfunct 20: 281-288.

22. Peyrat L, Haillot O, Bruyere F, Boutin JM, Bertrand P, et al. (2002) Prevalence and risk factors of urinary incontinence in young and middleaged women. BJU Int 89: 61-66

23. Brown SJ, Gartland D, Donath S, MacArthur C (2011) Effects of prolonged second stage, method of birth, timing of caesarean section and other obstetric risk factors on postnatal urinary incontince : an Australian nulliparous cohort study. BJOG 118: 991-1000.

24. Meyer S, De Grandi P, Schreyer A Caccia G (1996) The assessment of bladder neck position and mobility in continent nullipara, multipara,forcepsdelivered and incontinent women using perineal ultrasound: a future office procedure? Int Urogynecol J 7: 138-146.

25. Meyer S, Schreyer A, De Grandi P, Hohlfeld P (1998) The effect of birth on urinary continence mechanisms and other pelvic-floor characteristics. Obstet Gynecol 92: 613-618.

26. Meyer S, Hohlfeld P, Achtari C, Russolo A, De Grandi P (2000) Birth trauma: short and long term effects of forceps delivery compared with spontaneous delivery on various pelvic floor parameters. BJOG 107: 1360-1365.
27. Thom DH, Van Den Eeden SK, Brown JS (1997) Evaluation of parturition and other reproductive variables as risk factors for urinary incontinence in later life. Obstet Gynecol 90: 983-989.

28. Hsieh $\mathrm{CH}$, Su TH, Chang ST et al (2008) Prevalence of and attitude toward urinary incontinence in postmenopausal women. Int J Gynaecol Obstet 100: 171-174.

29. Jackson SL, Scholes D, Boyko EJ et al (2006) Predictors of urinary incontinence in a prospective cohort of postmenopausal women. Obste Gynecol 108: 855-862.

30. Shariat SF, Zimmern PE, Hilton K, Gruchalla RS (2009) Prospective questionnaire based evaluation of the prevalence of urinary incontinence in women with chronic cough. Urol Int 83: 181-186.

31. Melville JL, Katon W, Delaney K, Newton K (2005) Urinary incontinence in US women: a population-based study. Arch Intern Med 165: 537-542.

32. Melville JL, Walker E, Katon W, Lentz G, Miller J, et al. (2002) Prevalence of comorbid psychiatric illness and its impact on symptom perception, quality of life, and functional status in women with urinary incontinence. Am J Obstet Gynecol 187: 80-87.

33. van Gerwen M, Schellevis F, Lagro-Janssen T (2007) Comorbidities associated with urinary incontinence: a case-control study from the Second Dutch National Survey of General Practice. J Am Board Fam Med 20: $608-610$ 